\title{
Systemic Review on Chronic Myeloid Leukemia: Therapeutic Targets, Pathways and Inhibitors
}

Himansu Kumar, Utkarsh Raj, Saurabh Gupta, Rashmi Tripathi and Pritish Kumar Varadwaj

Indian Institute of Information Technology-Allahabad, Allahabad, UP, India

*Corresponding author: Pritish Kumar Varadwaj, Indian Institute of Information Technology-Allahabad, Allahabad, UP, India, Tel: +91-9454603259; E-mail: pritish.varadwaj@gmail.com

Received date: Aug 21, 2015, Accepted date: Oct 14, 2015, Publication date: Oct 19, 2015

Copyright: () 2015 Kumar H, et al. This is an open-access article distributed under the terms of the Creative Commons Attribution License; which permits unrestricted use; distribution; and reproduction in any medium; provided the original author and source are credited.

\begin{abstract}
Chronic Myeloid Leukemia (CML) is a stem cell disorder, characterized by the translocation of $9^{\text {th }}$ chromosome of Abelson (ABL) gene to the $22^{\text {th }}$ chromosome of breakpoint cluster region (BCR) gene. Consequently, translocation results into the chimeric oncogene BCR-ABL which encodes the BCR-ABL oncoprotein. CML is mainly a disease of adults but it can occur in any stage of life and it accounts around $15 \%$ of the all the types of leukemia. Various methods have been used to combat this disease like Chemotherapy, Radiation therapy; tyrosine kinase inhibitors etc., Imatinib as a tyrosine kinase inhibitor has dramatically improved the survival rate of CML patients, hence can be referred as first generation drug against the CML. Later on, recurrence of the disease in some treated patients has also been seen probably due to mutation in oncogenes. Researchers have started to find out more efficient tyrosine kinase inhibitors which can work on mutated oncoprotein and which can be referred as second or third generation drugs. In this review, special emphasis have been given to the carcinogenic mechanism of abnormal fusion of the BCR-ABL genes, current therapeutic options to prevent this disease, and Systems Biology approach to explore the CML associated biochemical pathways. Various advantages and disadvantages of the all therapeutic options to combat CML have also been discussed.
\end{abstract}

Keywords: CML; BCR-ABL; Imatinib; Radiation; Chemotherapy

\section{Introduction}

Chronic Myeloid Leukemia (CML) is probably the most studied human cancer because of its occurrence due to chromosomal abnormality and has been termed as Philadelphia Chromosome in 1960 [1]. In molecular investigation of the CML progression, it has been found that there is a translocation of Abelson (ABL) gene from $9^{\text {th }}$ chromosome to the $22^{\text {th }}$ chromosome of the Break Point Cluster genes and form a hybrid gene that is BCR-ABL oncogene [2]. The BCR-ABL gene encodes the oncoprotein namely BCR-ABL oncoprotein. Consequently this abnormal oncoprotein enhance the tyrosine kinase activity of the cells which are responsible for growth and replication by down regulating the associated pathways like Autophosphorylation, JAK/STAT, MAPK, RAS, RAF, JUN kinase, MYC etc. [3]. In continuation of the molecular analysis, ABL gene encodes a non receptor tyrosine kinase and homologous to the Abelosn murine leukemia virus. The ABL gene comprises of various structural domains, out of them three SRC homologous (SH-1, 2, and 3) are present towards the $\mathrm{NH} 2$ terminal [4]. Out of which, $\mathrm{SH} 1$ domain is responsible for tyrosine kinase activity, whereas $\mathrm{SH} 2$ and $\mathrm{SH} 3$ domains are involved in regulating the interaction activity of the BCR-ABL oncoprotein with other proteins [5].

It has been reported that ABL gene (which is expressed as $145-\mathrm{kd}$ protein) is actively involved in the process of cell regulation and apoptosis with the help of extracellular and intracellular signals [5]. Likewise Break Point Cluster Region (BCR) gene encodes 160-kd oncoprotein and it consists of several structural motifs. The N-terminal exon encodes the serine-threonine kinase, whereas coiled domains of the exon region allowed BCR to dimerized [6]. The C-terminal region of BCR consists of the GTPase which regulates the activity of Rac and consequently regulates the actin polymerization [7]. It has been noticed that, BCR can phosphorylate on various tyrosine residues especially T177 by binding with an adaptor Grb-2 and regulate the activation of Ras pathway [8]. Detail mechanism and domain orientation of the BCR-ABL protein is schematically represented into Figure 1.

This chimeric rearrangement of both the protein is also referred as the Philadelphia chromosome. The molecular consequence of this newly formed BCR-ABL fusion oncogene, which in turn translates into a Bcr-Abl oncoprotein and resulted into CML [6-9].

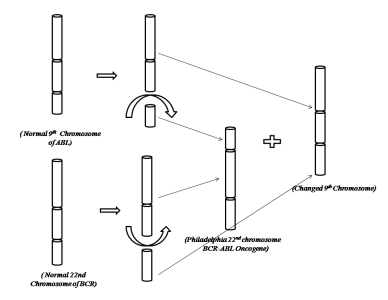

Figure 1: (A) Mechanism of BCR-ABL (breakpoint cluster regionAbelson) fusion and formation of Chronic Myeloid Leukemia causing agent.

\section{Stages of the CML}

CML is a result of abnormal production of white blood cells by bone marrow cells. Proliferated leukemic cell starts affecting White blood cells, Red blood cells, and platelets [10]. CML usually occurs at adult 
stage and rarely occurs at early stage of life with symptoms like fever, night sweats, and tiredness. There are three phases of chronic myeloid leukemia namely Chronic phase, Accelerated phase, and Blast phase [11]. Chronic is the most primitive stage of this disease, and it can be diagnosed by identifying simple symptoms like tiredness and fatigues, but sometimes symptoms mild and are not identifiable. If chronic phase passes away without getting noticed it ultimately enters into accelerated phase. In this stage CML cells becomes aggressive and is easily noticeable by analyzing symptoms consequently, Accelerated phase converted into Blast phase which is most aggressive and harmful to the patients. Most of the symptoms of Blast phase are similar to the Acute Myeloid Leukemia [10,11].

\section{Pathways Associated with Chronic Myeloid Leukemia}

Multiple interlinked pathways have been reported that BCR-ABL influenced the PI3K/AKT/Mtor/JAK-STAT/RAF-RAS-MAPK pathways. Along with tyrosine kinase inhibition identification of common component of above said pathways can be a good therapeutic approach.

\section{Ras and MAP kinase pathways and targets}

It's a signaling pathway by which cells receives the signal from receptor of the cell surface and communicate with the series of proteins in the cell and transmits signals to the nucleus. Signaling process starts by binding of the receptor molecule with the signaling molecule and ends with the binding of nucleus subsequently produces the changes into the systems like cell division [11-13]. Various reports had confirmed about the association between Ras and MAP kinase pathway with BCR-ABL protein.

The small ligand molecule Grb-2 and SOS autophosphorylate the reactions by binding with the tyrosine 177 docking site and activate the Ras shown in ref. [13]. Whereas other two adapter molecules like Shc and Crkl binds with $\mathrm{SH} 2$ and $\mathrm{SH} 3$ domains of BCR-ABL protein respectively and activates the Ras and MAPK pathways. Any abnormality in the chain reactions leads to the abnormal proliferation of the BCR-ABL protein and causes CML $[14,15]$.

Figure 2: Symbolic representation of RAS-MAP (Mitogen Activated Protein) kinase pathway.

The activation of Ras by another ligand molecule like Crkl is still not clear because it is limited to the fibroblast only that's why interaction between BCR-ABL and Crkl is not confirmed for transformation of myeloid cells [15-17]. Some evidence about involvement of Ras activity in pathogenesis of Philadelphia positive cells have been reported because of less common mutation presence even in Blast phase of the disease [18,19].

Raf initiates a signaling cascade through the serine-threonine kinases Mek1/Mek2 and Erk, which ultimately leads to the activation of gene transcription as shown in Figure 2 [20-22].

\section{Jak-Stat pathway and targets}

JAK-STAT pathway is highly expressed in white blood cells (WBC) and abnormal proliferation of the WBC is the cause of CML progression. This pathway is actively participating into the transcription process of the cells by transmitting the signal from outer environment of the cells through cell membrane and binds to the promoter of the nucleus. Phosphorylation of the transcription factors like STAT1-STAT5 is being reported in various CML literatures [20]. STAT5 significantly contributes during malignant cells transformation [23]. JAK/STAT signal transduction pathway is regulated by the two STAT3 phosphatases, PP1 and PP2.

Theses phosphates influence the activation of STAT component in the both cytosol and the nucleus. In this pathway as shown in Figure 3, IL-6 binds to its receptor gp80, which is not a part of the signaling process of the receptor. The receptor gp130 which is a part of the signaling process, attaches to the protein tyrosine kinases of the JAK family. Then IL-6-gp80 complex binds to the compound gp130/JAK to form the complex IL6-gp80-gp130-JAK. Formation of this complex results in the dimerization of the complex IL6-gp80-gp130-JAK to form (IL6-gp80-gp130-JAK)2.

SHP-2 binds to the phosphorylated dimer complex (IL6-gp80gp130-JAK)2 to form (IL6-gp80-gp130-JAK)*2-SHP-2 complex which act as the point of initiation for both the MAPK and the JAK/STAT pathway. In the JAK/STAT signaling pathway, the phosphorylated dimer, (IL6-gp80-gp130-JAK) ${ }^{\star}$ recruits the transcription factor STAT3.

The phosphorylation of the component STAT3 leads to its dissociation from the (IL6-gp80-gp130-JAK)2 complex and further undergoes the process of dimerization. The dimerized complex of the STAT3 then enters into the nucleus to undergo dephosphorylation and is transferred back again into the cytosol for the cycle of phosphorylation-dephosphorylation cycle.

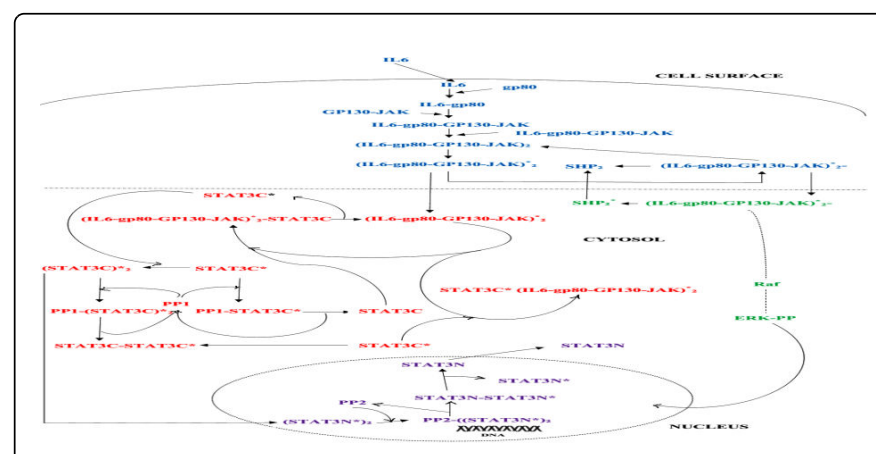

Figure 3: Symbolic representation of JAK-STAT and MAPK Pathway. 
Citation: Kumar H, Raj U, Gupta S, Tripathi R, Varadwaj PK (2015) Systemic Review on Chronic Myeloid Leukemia: Therapeutic Targets, Pathways and Inhibitors. J Nucl Med Radiat Ther 6: 257. doi:10.4172/2155-9619.1000257

Page 3 of 7

In Figure 3, Interaction between JAK-STAT and MAPK pathway have been described and can be seen that some of the molecules are involved in activation of other pathway's molecule.

\section{PI3 kinase pathway and targets}

PI3 kinase pathway is directly related to the various cellular functions like cell division, cell differentiation, cell proliferation etc. It has been reported that PI3 kinase is highly expressed in BCR-ABL proliferation process. It forms complexes with $\mathrm{Cbl}$, and adapter molecules like Crk and Crkl [24].

Membrane receptor has been catalyzed by the interaction with subunit of class I PI3Ks after receiving the extracellular signals. Catalyzed PI3Ks produces the PIP2 and PTEN, and deactivation of PI3Ks has been occurred due to dephosphorylation of PIP3 into PIP2 and acts as regulatory molecule of this pathway. PIP3 is activated by the binding of Pleckstrin Homology $(\mathrm{PH})$ domains of the proteins and deposited to the cell membrane.

PIP3 is down regulated by the serine threonine kinase AKT/ PKB effectors. Binding of the PIP3 and PH domain activates the deposition of AKT to the membrane and activates the phosphorylation [25]. Schematic representation of the pathway has been shown in Figure 4.

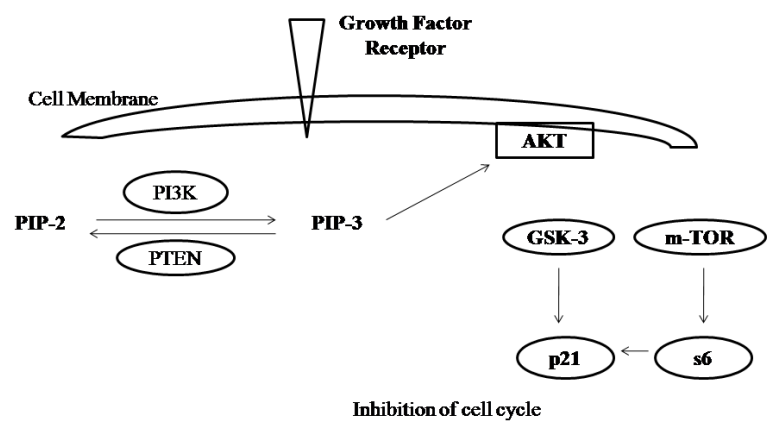

Figure 4: Symbolic representation of PI3 kinase pathway.

\section{Myc pathway and targets}

The Myc pathway is also highly expressed in various cellular processes like cell division, cell differentiation, proliferation, apoptosis etc. The mutation caused in pathways results into various types of malignancy [26]. It has been reported that Myc works as transcription factor, however its target is still unknown. Myc binds with the SH2 domain of the BCR-ABL protein and over expression of it causes the excessive proliferation of BCR-ABL [27].

Myc protein acts a transcription factor which activates the expression of genes by binding with enhancer box sequences (E-box) and histone acetyltransferases (HATs).

Myc protein is also known as transcriptional repressor because it inhibits the Miz-1target gene by binding with Miz-1 and replacement of p300 co-activator. Myc pathway is directly associated with the DNA replication [28].

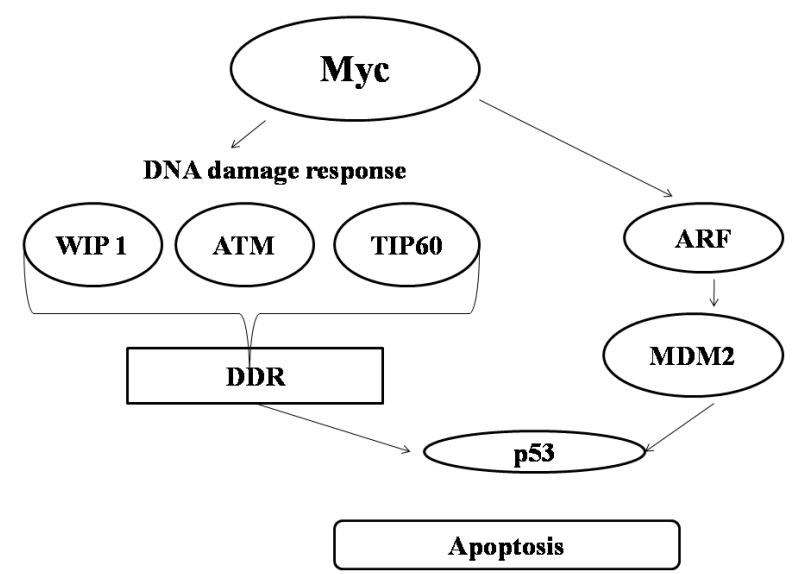

Figure 5: Schematic representation of Myc pathway.

The direct association of Myc pathway with the BCR-ABL progression is still poorly understood, however some report suggests that transformation of $\mathrm{v}$-abl is activated by the Ras/Raf, cdks, E2F transcription factors which ultimately affects the Myc promoter $[28,29]$.

It has been noticed that effects of Myc on Philadelphia positive cells are almost similar to the other tumor cells like proliferation and apoptotic signals [30-32]. Schematic representation of the pathway has been shown in Figure 5.

\section{Important Components from the Various Pathways and their Targets}

All significant components from the related pathways of chronic myeloid leukemia like Tozasertib, Bafetinib, Nilotinib, Dasatinib, Imatinib, Ponatinib, Bosutinib, Saracatinib etc. were collected and shown in Table 1. Respective targets of the each inhibitors are also been listed into the Table 1 with their PubChem ID.

\begin{tabular}{|l|l|l|l|}
\hline $\begin{array}{l}\text { S. } \\
\text { No. }\end{array}$ & $\begin{array}{l}\text { Reference } \\
\text { Molecules }\end{array}$ & $\begin{array}{l}\text { PubChem } \\
\text { ID }\end{array}$ & Targets \\
\hline 1 & Tozasertib & 5494449 & Aurora A,B, and C, FLT, Bcr-Abl \\
\hline 2 & Bafetinib & 24853523 & Abl, Lyn \\
\hline 3 & Nilotinib & 644241 & Bcr-Abl \\
\hline 4 & Dasatinib & 3062316 & Abl, Src, c-Kit \\
\hline 5 & Imatinib & 5291 & Abl, PDGFR, c-Kit \\
\hline 6 & Ponatinib & 24826799 & Abl, PDGFRa, VEGFR2, FGFR1 \\
\hline 7 & Bosutinib & 5328940 & Abl, Src \\
\hline 8 & Saracatinib & 10302451 & Src, EGFR, LCK, c-YES \\
\hline
\end{tabular}

Table 1: Reference molecules approved by FDA, their Pubchem ID, and their known targets. 


\section{Therapeutic approaches to combat CML}

There are three phase of the CML progression namely chronic, accelerated, and blast, out of these three phases chronic is a long lasting and primitive one. Whereas accelerated and blast are advanced and having reduced effect of the any treatment options like chemotherapy, stem cell transplantations, TKI etc. However for advanced stage patients stem cell transplantation option may be the preferred therapy if donor of the stem cells available. Specifically for the accelerated and blast phases, TKI like Dasatinib, Nilotinib etc are being reported significant.

However, after discovery of the Imatinib as a small molecule inhibitor for the targeting of causative agent BCR-ABL oncoprotein, survival rate of the patients have been remarkably improved specially in the case of chronic phase of the CML patients.

\section{Non-specific agent}

Initial days, treatment process of the CML were completely based on non-specific agent like busulfan, hydroxyurea, and interferonalfa (INFa). These agents were able to improve the survival rate of the patients but their side effect like multitude of toxicities and probability of reoccurrence hinders the treatment process [33].

\section{Stem cell transplantation}

In continuation, Stem cell transplantation becomes second alternative of the CML treatment process, but its high risk of morbidity and mortality and lack of appropriate stem cell donor limits this technique [33].

\section{Chemotherapy}

Chemotherapy is useful in CML because through this technique patients have been treated by the certain dose of drug through vein or may be through mouth by which drugs enter in to the circulatory systems of the body and spread out into the whole body. Chemotherapy refers that the agent (hydroxyurea, busulfan, cyclophoshamide etc) which can specifically kill the abnormally growing cells. It was the extensively practiced treatment option decades ago [34].

Major limitations of this treatment are killing of non cancerous rapid dividing cells like bone marrow cells, the lining of the mouth and intestines, and the hair follicles etc which cause serious side effects like hair loss, mouth sores, loss of appetite, nausea and vomiting, Low white blood cell counts (leukopenia), which increases the risk of serious infection, Low blood platelet counts (thrombocytopenia), which can lead to easy bruising or bleeding, Low red blood cell counts [35].

\section{Radiation therapy}

Radiation therapy is used in a number of cancer cells treatments, especially when cancerous cells are localized in a particular area. It is used by bombarding the high energy rays on a particular cancerous population and destroy them [36]. In Chronic Myeloid Leukemia, radiation therapy is not used as primary treatment, it is used in certain cases of the CML. Mainly it assists the chemotherapy by reducing the swollen internal organs like spleen. Sometimes low dose of radiations are given before the Stem cell transplantation treatment process of the CML.
Apart from its significance, there are some side effects of the radiation therapies which are as follows: Fatigue, skin changes (like redness, blistering, and peeling), mucositis, nausea, vomiting, diarrhea, low blood counts etc. [37].

\section{Tyrosine kinase inhibitors}

After establishment of fact that the interaction of BCR and ABL protein is a causing agent, thereafter scientific community have started to find out the way through which interaction can be hampered and subsequently oncogenic activity or cancerous proliferation can be stopped. First success they have achieved after discovery of the Imatinib (STI-571), a small molecule that can inhibit the interaction by blocking the $\mathrm{SH} 2$ and $\mathrm{SH} 3$ domain of the ABL protein [38]. The FDA has approved Imatinib as first tyrosine kinase inhibitor drug in 2001, after discovery of Imatinib the entire arena of the CML treatment process has changed and patient's survival rate has increased remarkably) from 20 to $80-90 \%$ [39]. FDA has approved two more tyrosine kinase inhibitor like dasatinib, and nilotinib, after success of Imatinib. These drugs are referred as first generation of drug against the CML [40] shown in Figure 6.

\section{Imatinib}

Imatinib mesylate, (Gleevec, Novartis Pharmaceutical Corporation, $\mathrm{NJ}$ ), a small molecule that can be used as a drug at chronic phase of the CML patients. It competitively inhibits the ATP binding site of the BCR-ABL protein and inhibits the phosphorylation process of cell signaling transduction. Clinical investigators have performed trial on 1106 patients by giving the dose of $400 \mathrm{mg} /$ day till nineteenth months under the organization IRIS (International Randomized Study of Interferon and STI571).

In contrary around $30 \%$ patients didn't show anticipating response, which led the investigator to find out the second or third generation drugs against the CML. Many reasons have been drawn for the intolerance of Imatinib against the CML like point mutation of the specific residues like T315I, Y253H and F255K etc. Point mutation between Threonine and Isoleucine on 315 positions is also referred as Gatekeeper mutation which can be observed in 4-15\% Imatinib resistant patients [41].

Imatinib is a derivative of 2-phenyl amino pyrimidine and it accommodates with the active site of tyrosine kinase leads to reduction of activity. Imatinib is highly specific about binding with the receptor, however large numbers of tyrosine kinase receptors are available in the body but it acts against with ABL, c-kit, PDGFR etc only [42].

Tyrosine kinase receptor has ATP binding sites, where transfer of terminal phosphate group from ATP takes place and phosphorylation occurs. In case of BCR-ABL tyrosine kinase, Imatinib binds with the binding site by competitive inhibition with the ATP and blocks the space for ATP [43].

\section{Nilotinib}

In further continuation of drug discovery process of the Imatinib resistant CML cells, Nilotinib is a structural analogue of the Imatinib. It is produced as Tasigna, by Novartis Pharmaceutical Corporation and proven as 50 times better efficiency in terms of ATP binding affinity with BCR-ABL protein. Nilotinib gives the excellent outcomes in terms of survival rate [44]. 
Page 5 of 7

\section{Multi Target Approach}

Above said first generation drugs like Imatinib, Nilotinib, and Dasatinib are invented for the inhibition of BCR-ABL fusion. Further it has been noticed that apart from BCR-ABL protein there are some other targets like SRC, STAT1, STAT3, STAT5, PDGFR etc., which are also involved in progression of this disease. Multi target inhibition by single inhibition has already been practiced in various severe disease combat strategies [40-44].

\section{Dasatinib}

Dasatinib is orally taken drug of CML and analogous to the Imatinib but in terms of efficiency it's 350 times efficient as compared to Imatinib. It is in market with the brand name Sprycel and produced by Bristol-Myers Squibb. Dasatinib is equally efficient against the BCR$\mathrm{ABL}$ as well as SRC receptors [45]. It has been clinically approved that Dasatinib is a proven drug against chronic phase of the disease, Imatinib resistant cells, as well as newly treated patients [44,45].

\section{Ponatinib}

Ponatinib has been discovered as multi-targeted tyrosine-kinase inhibitor, orally taken and marketed as Iclusig, and produced by the ARIAD Pharmaceuticals. It has been designed in a manner that it can efficiently inhibit the Imatinib resistant CML cells. This drug has been approved in 2012 by the FDA, but a ban has been imposed till Oct 2013 because some of the side effects like blood clot into the treated patients, but after rectification it is now widely used [46].

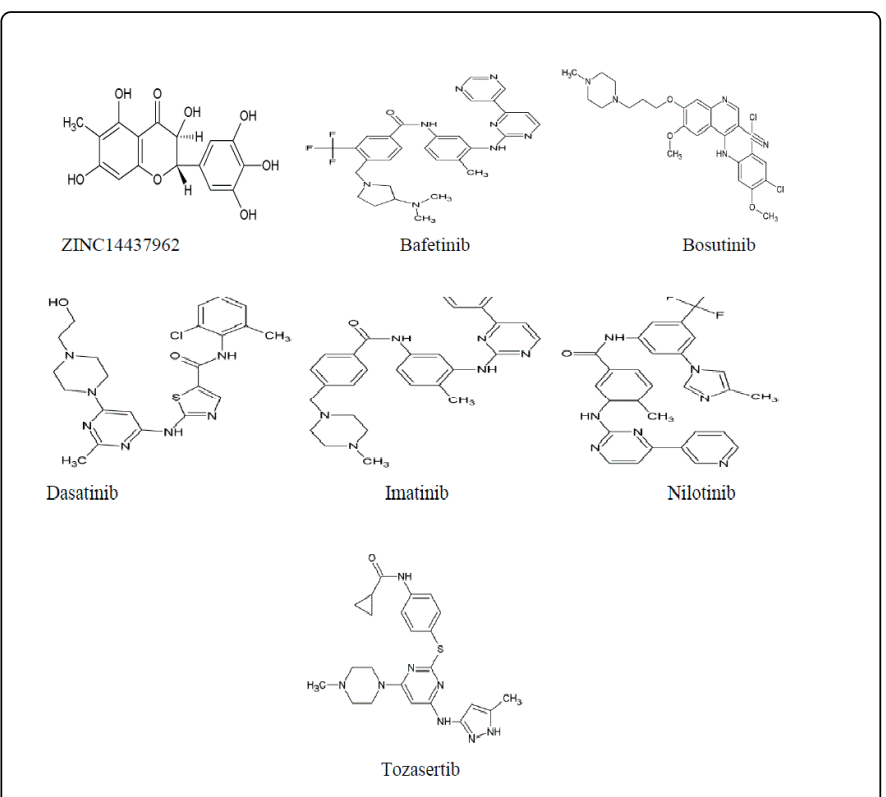

Figure 6: 2-D structures of the FDA approved inhibitors available for BCR-Abl and Src receptors.

After successful implementation of the Ponatinib as multi receptor inhibitors, many organizations have started to find out some more potent natural inhibitors which can bind to the multiple CML causing agent and efficiently inhibit the CML progression $[45,46]$.

Some of the Bioinformatics approaches like virtual screening, molecular docking, molecular dynamics simulation, and ADMET analysis become significant to get the small molecules which can be able to inhibit the multiple receptors. A recent study has been reported about the multi receptor inhibitors described in Table 2 [47]. In this study, small natural molecules have been screened out from the huge available natural databases. Reported molecules give the better result as compared to available single receptor inhibitor like Imatinib, Dasatinib, Nilotinib etc.

\begin{tabular}{|l|l|l|l|}
\hline S. No. & Inhibitors & $\begin{array}{l}\text { Docking Score } \\
\text { with (BCR-ABL) }\end{array}$ & $\begin{array}{l}\text { Docking Score } \\
\text { With (SRC) }\end{array}$ \\
\hline 1 & ZINC14437962 & -9.493 & -9.513 \\
\hline 2 & Bafetinib & -4.678 & -7.085 \\
\hline 3 & Bosutinib & -4.686 & -5.719 \\
\hline 4 & Dasatinib & -5.126 & -8.794 \\
\hline 5 & Imatinib & -5.746 & -7.831 \\
\hline 6 & Nilotinib & -5.590 & -8.129 \\
\hline 7 & Tozasertib & -5.673 & -7.957 \\
\hline
\end{tabular}

Table 2: Comparison of the Docking scores of the inhibitors available for BCR-Abl and Src receptors.

\section{Cytogenetic response}

Ultimate goal of all the therapeutic options are to eliminate the leukemic stem cell populations from the patients for that cytogenetic analysis remains the standard options to monitor [3]. It has been reported that treatment through TKIs, patients are able to get complete molecular response. Through RTPCR, it has been observed the patients sample shows absence of the BCR-ABL transcripts. Second generation TKIs like Dasatinib and Nilotinib shows even better cytogenetic response [4]. However complete molecular responses against the leukemic cells are still matter of investigation.

\section{Conclusion}

Successful trials of tyrosine kinase inhibitor like Imatinib has dramatically improved the survival rate of the CML patients and has drastically reduced the mortality rate to $1-2 \%$. Moreover multiple therapeutic options involving various tyrosine kinase inhibitors like Imatinib, Nilotinib, Dasatinib, Bosutinib, and Ponatinib are being utilized extensively for treatment of CML patients. In view of the recent reports suggesting probable mutations in receptor sites the effectiveness of above said inhibitors are often questionable. Hence the multi target receptor inhibitors like Ponatinib became more potent alternative as compared to other single target inhibitors. The multi target inhibitors not only posses higher potency but also often shows low failure rate because of the tendency to avoid mutated active site. The effectiveness of dual inhibitors were being studied suggesting the ability of these inhibitors to interact with at least one of the reported drug targets for CML.

\section{Acknowledgement}

The authors are thankful to the Indian Institute of Information Technology Allahabad, UP, India for providing all required facility to complete this review. 


\section{References}

1. Nowell P, Hungerford D (2004) A minute chromosome in human chronic granulocytic leukemia. Landmarks in Medical Genetics: Classic Papers with Commentaries 132: 103.

2. Rowley JD (1973) A new consistent chromosomal abnormality in chronic myelogenous leukemia identified by quinacrine fluorescence and Giemsa staining. Nature 243: 290-293.

3. Bartram CR, de Klein A, Hagemeijer A, van Agthoven T, Geurts van Kessel A, et al. (1983) Translocation of c-ab1 oncogene correlates with the presence of a Philadelphia chromosome in chronic myelocytic leukaemia. Nature 306: 277-280.

4. Abelson HT, Rabstein LS (1970) Lymphosarcoma: virus-induced thymicindependent disease in mice. Cancer Res 30: 2213-2222.

5. Cohen GB, Ren R, Baltimore D (1995) Modular binding domains in signal transduction proteins. Cell 80: 237-248.

6. McWhirter JR, Galasso DL, Wang JY (1993) A coiled-coil oligomerization domain of $\mathrm{Bcr}$ is essential for the transforming function of $\mathrm{Bcr}-\mathrm{Abl}$ oncoproteins. Mol Cell Biol 13: 7587-7595.

7. Denhardt DT (1996) Signal-transducing protein phosphorylation cascades mediated by Ras/Rho proteins in the mammalian cell: the potential for multiplex signalling. Biochem J 318 : 729-747.

8. Ma G, Lu D, Wu Y, Liu J, Arlinghaus RB (1997) Bcr phosphorylated on tyrosine 177 binds Grb2. Oncogene 14: 2367-2372.

9. Quintás-Cardama A, Cortes J (2009) Molecular biology of bcr-abl1positive chronic myeloid leukemia. Blood 113: 1619-1630.

10. Deininger MW, Vieira S, Mendiola R, Schultheis B, Goldman JM, Melo JV (2000) BCR-ABL tyrosine kinase activity regulates the expression of multiple genes implicated in the pathogenesis of chronic myeloid leukemia. Cancer Res 60: 2049-2055.

11. Heaney C, Kolibaba K, Bhat A, Oda T, Ohno S, et al. (1997) Direct binding of CRKL to BCR-ABL is not required for BCR-ABL transformation. Blood 89: 297-306.

12. Watzinger F, Gaiger A, Karlic H, Becher R, Pillwein K, et al. (1994) Absence of $\mathrm{N}$-ras mutations in myeloid and lymphoid blast crisis of chronic myeloid leukemia. Cancer Res 54: 3934-3938.

13. Pendergast AM, Quilliam LA, Cripe LD, Bassing CH, Dai Z, et al. (1993) BCR-ABL-induced oncogenesis is mediated by direct interaction with the SH2 domain of the GRB-2 adaptor protein. Cell 75: 175-185.

14. Oda T, Heaney C, Hagopian JR, Okuda K, Griffin JD, et al. (1994) Crkl is the major tyrosine-phosphorylated protein in neutrophils from patients with chronic myelogenous leukemia. J Biol Chem 269: 22925-22928.

15. Pelicci G, Lanfrancone L, Salcini AE, Romano A, Mele S, et al. (1995) Constitutive phosphorylation of Shc proteins in human tumors. Oncogene 11: 899-907.

16. Bhat A, Kolibaba K, Oda T, Ohno-Jones S, Heaney C, et al. (1997) Interactions of CBL with BCR-ABL and CRKL in BCR-ABL-transformed myeloid cells. J Biol Chem 272: 16170-16175.

17. Salgia R, Uemura N, Okuda K, Li JL, Pisick E, et al. (1995) CRKL links p210BCR/ABL with paxillin in chronic myelogenous leukemia cells. J Biol Chem 270: 29145-29150.

18. Chu S, Holtz M, Gupta M, Bhatia R (2004) BCR/ABL kinase inhibition by imatinib mesylate enhances MAP kinase activity in chronic myelogenous leukemia CD34+ cells. Blood 103: 3167-3174.

19. Marais R, Light Y, Paterson HF, Marshall CJ (1995) Ras recruits Raf-1 to the plasma membrane for activation by tyrosine phosphorylation. EMBO J 14: 3136-3145.

20. Cahill MA, Janknecht R, Nordheim A (1996) Signalling pathways: jack of all cascades. Curr Biol 6: 16-19.

21. Kabarowski JH, Allen PB, Wiedemann LM (1994) A temperature sensitive p210 BCR-ABL mutant defines the primary consequences of BCR-ABL tyrosine kinase expression in growth factor dependent cells. EMBO J 13: 5887-5895.
22. Cortez D, Reuther G, Pendergast AM (1997) The Bcr-Abl tyrosine kinase activates mitogenic signaling pathways and stimulates G1-to-S phase transition in hematopoietic cells. Oncogene 15: 2333-2342.

23. Raitano AB, Halpern JR, Hambuch TM, Sawyers CL (1995) The Bcr-Abl leukemia oncogene activates Jun kinase and requires Jun for transformation. Proc Natl Acad Sci U S A 92: 11746-11750.

24. Skorski T, Wlodarski P, Daheron L, Salomoni P, Nieborowska-Skorska M, et al. (1998) BCR/ABL-mediated leukemogenesis requires the activity of the small GTP-binding protein Rac. Proc Natl Acad Sci U S A 95: 11858-11862.

25. Bedi A, Zehnbauer BA, Barber JP, Sharkis SJ, Jones RJ (1994) Inhibition of apoptosis by BCR-ABL in chronic myeloid leukemia. Blood 83: 2038-2044.

26. Shi CS, Tuscano JM, Witte ON, Kehrl JH (1999) GCKR links the Bcr-Abl oncogene and Ras to the stress-activated protein kinase pathway. Blood 93: $1338-1345$

27. Montaner S, Perona R, Saniger L, Lacal JC (1998) Multiple signalling pathways lead to the activation of the nuclear factor kappaB by the Rho family of GTPases. J Biol Chem 273: 12779-12785.

28. Diekmann D, Brill S, Garrett MD, Totty N, Hsuan J, et al. (1991) Bcr encodes a GTPase-activating protein for p21 rac. Nature 351: 400-402.

29. Sawyers CL, Callahan W, Witte ON (1992) Dominant negative MYC blocks transformation by ABL oncogenes. Cell 70: 901-910.

30. Zou X, Rudchenko S, Wong K, Calame K (1997) Induction of c-myc transcription by the $\mathrm{v}-\mathrm{Abl}$ tyrosine kinase requires Ras, Raf, and cyclindependent kinases. Genes Dev 11: 654-662.

31. Stewart MJ, Litz-Jackson S, Burgess GS, Williamson EA, Leibowitz DS, et al. (1995) Role for E2F1 in p210 BCR-ABL downstream regulation of cmyc transcription initiation. Studies in murine myeloid cells. Leukemia 9: 1499-1507.

32. Bissonnette RP, Echeverri F, Mahboubi A, Green DR (1992) Apoptotic cell death induced by c-myc is inhibited by bcl-2. Nature 359: 552-554.

33. Evan GI, Wyllie AH, Gilbert CS, Littlewood TD, Land H, et al. (1992) Induction of apoptosis in fibroblasts by c-myc protein. Cell 69: 119-128.

34. Verfaillie CM, Hurley R, Lundell BI, Zhao C, Bhatia R (1997) Integrinmediated regulation of hematopoiesis: do BCR/ABL-induced defects in integrin function underlie the abnormal circulation and proliferation of CML progenitors? Acta Haematol 97: 40-52.

35. Bhatia R, Wayner EA, McGlave PB, Verfaillie CM (1994) Interferon-alpha restores normal adhesion of chronic myelogenous leukemia hematopoietic progenitors to bone marrow stroma by correcting impaired beta 1 integrin receptor function. J Clin Invest 94: 384-391.

36. Zhao RC, Tarone G, Verfaillie CM (1997) Presence of the adhesion inhibitory b1B integrin isoform on CML but not normal progenitors is at least in part responsible for the decreased CML progenitor adhesion [abstract]. Blood 90: 393a.

37. Lewis JM, Baskaran R, Taagepera S, Schwartz MA, Wang JY (1996) Integrin regulation of $\mathrm{c}$-Abl tyrosine kinase activity and cytoplasmicnuclear transport. Proc Natl Acad Sci U S A 93: 15174-15179.

38. Uemura N, Griffin JD (1999) The adapter protein Crkl links Cbl to C3G after integrin ligation and enhances cell migration. J Biol Chem 274: 37525-37532.

39. Sattler M, Salgia R, Okuda K, Uemura N, Durstin MA, et al. (1996) The proto-oncogene product $\mathrm{p} 120 \mathrm{CBL}$ and the adaptor proteins CRKL and cCRK link c-ABL, p190BCR/ABL and p210BCR/ABL to the phosphatidylinositol-3' kinase pathway. Oncogene 12: 839-846.

40. Salgia R, Pisick E, Sattler M, Li JL, Uemura N, et al. (1996) p130CAS forms a signaling complex with the adapter protein CRKL in hematopoietic cells transformed by the BCR/ABL oncogene. J Biol Chem 271: 25198-25203.

41. Sattler M, Salgia R, Shrikhande G, Verma S, Uemura N, et al. (1997) Differential signaling after betal integrin ligation is mediated through binding of CRKL to p120(CBL) and p110(HEF1). J Biol Chem 272: 14320-14326. 
Citation: Kumar H, Raj U, Gupta S, Tripathi R, Varadwaj PK (2015) Systemic Review on Chronic Myeloid Leukemia: Therapeutic Targets, Pathways and Inhibitors. J Nucl Med Radiat Ther 6: 257. doi:10.4172/2155-9619.1000257

Page 7 of 7

42. Bazzoni G, Carlesso N, Griffin JD, Hemler ME (1996) Bcr/Abl expression stimulates integrin function in hematopoietic cell lines. J Clin Invest 98 521-528.

43. Senechal K, Halpern J, Sawyers CL (1996) The CRKL adaptor protein transforms fibroblasts and functions in transformation by the BCR-ABL oncogene. J Biol Chem 271: 23255-23261.

44. Novartis Pharma AG (2003) Gleevec ${ }^{\oplus}$ (imatinib mesylate) tablets prescribing information. East Hanover, NJ; 2006 Sep. Anon. Drugs of choice for cancer. Treat Guidel Med Lett: 41-52.

45. http://www.fda.gov.
46. Huang WS, Metcalf CA, Sundaramoorthi R, Wang Y, Zou D, et al. (2010). Discovery of 3-[2-(imidazo[,2-b]pyridazin-3-yl)ethynyl]-4-methyl-N-\{4[(4-methylpiperazin-1-yl) methyl]-3-(trifluoromethyl)phenyl\}benzamide (AP24534), a potent, orally active pan-inhibitor of breakpoint cluster region-abelson (BCR-ABL) kinase including the T315I gatekeeper mutant. J. Med. Chem 53: 4701-4719.

47. Kumar H, Raj U, Srivastava S, Gupta S, Varadwaj PK (2015) Identification of Dual Natural Inhibitors for Chronic Myeloid Leukemia by Virtual Screening, Molecular Dynamics Simulation and ADMET Analysis. Interdiscip Sci Comput Life Sci 7: 1-1. 